\title{
Alface em canteiro econômico integrado ao sistema de irrigação cuca de umbu no município de Salgueiro, Pernambuco
}

\section{Lettuce in an economic plot integrated to the irrigation system cuca de umbu in the municipality of Salgueiro, Pernambuco, Brazil}

\author{
Daniel de Carvalho Leite ${ }^{(1)}$, Elton Carlos Pereira Vieira de Alencar Teles ${ }^{\left(\mathbb{D}^{2}\right.}$, Francisco Dirceu Duarte \\ Arraes (D) $^{3}$, Jânio Eduardo de Araújo Alves (D) $^{4}$
}

\begin{abstract}
${ }^{1}$ Mestre em Extensão Rural e Desenvolvimento Local, Universidade Federal Rural de Pernambuco. Engenheiro Agrônomo no Projeto de Integração do Rio São Francisco/Universidade Federal do Vale do São Francisco, Petrolina, Pernambuco. Tel. (87)9.9104-1262. E-mail: carvalho.leite@hotmail.com; ${ }^{2}$ Mestre em Engenharia Agrícola, Universidade Federal do Vale do São Francisco. Engenheiro Agrônomo Autônomo, Salgueiro, Pernambuco. Tel. (87)9.9191-5292. E-mail: eltonteles@hotmail.com; ${ }^{3}$ Graduado em Irrigação e Drenagem, Mestre em Engenharia Agrícola e Doutor em Ciência (Física do Ambiente Agrícola) pela Universidade de São Paulo. Professor do Instituto Federal de Educação, Ciência e Tecnologia do Sertão Pernambucano, campus Salgueiro. Tel. (88)9.9613-7048 Email: dirceu.arraes @ifsertao-pe.edu.br; ${ }^{4}$ Graduado em Gestão Ambiental e Especialista em Educação Ambiental e Sustentabilidade. Técnico do Laboratório de Agroindústria do Instituto Federal de Educação, Ciência e Tecnologia do Sertão Pernambucano, campus Salgueiro. Tel. (87)9.9104-8514. E-mail: janioedu87@hotmail.com.
\end{abstract}

A R T I G O

Recebido: 08/11/2018

Aprovado: 14/03/2019

\section{Palavras-chave:}

Lactuca sativa $\mathrm{L}$.

Eficiência no uso da água

Irrigação convencional

Key words:

Lactuca sativa L.

Efficiency in water use

Conventional irrigation.

\section{R E S U M O}

O sistema de irrigação, denominado cuca de umbu, pode ser uma alternativa eficiente e vantajosa para os agricultores familiares na produção de alface em canteiro econômico. Nesse sentido, objetivou-se avaliar a produção de alface no canteiro econômico integrado ao sistema de irrigação cuca de umbu com o canteiro convencional irrigado manualmente com regador em propriedade familiar no município de Salgueiro, Pernambuco. O experimento constitui-se de dois tratamentos, canteiro econômico e o convencional com quatro repetições, avaliou-se o número médio de folhas por planta; altura média de plântulas; diâmetro da planta e do caule; massa fresca e seca da parte aérea e da raiz; comprimento da raiz; e eficiência no uso da água. A eficiência no uso da água foi superior em 2,92\% para os canteiros convencionais, porém, com exceção do comprimento da raiz que foi $2,19 \mathrm{~cm}$ maior nos canteiros convencionais, todos as demais variáveis evidenciam que a produção foi melhor para os canteiros econômicos, havendo diferença significativa para a massa fresca das plantas que foi $103,430 \mathrm{~g} /$ planta maior nos canteiros econômicos, a altura de plantas $3,81 \mathrm{~cm}$ e o diâmetro caule $0,19 \mathrm{~cm}$.

A B S T R A C T
The irrigation system, called umbu cuca, can be an efficient and advantageous alternative
for the family farmers in the production of lettuce in economical land. The aim of this study
was to evaluate the lettuce production at the economic site integrated to the umbu cuca
irrigation system with the conventional irrigated manure with irrigation system in the
municipality of Salgueiro, Pernambuco, Brazil. The experiment consisted of two treatments,
economical and conventional with four replications, the average number of leaves per plant
was evaluated; mean height of seedlings; diameter of plant and stem; fresh and dry mass of
shoot and root; root length; and water use efficiency. After collection, the data were
submitted to the test with $5 \%$ probability. The water use efficiency was $2.92 \%$ higher for
conventional beds, but with the exception of root length that was $2.19 \mathrm{~cm}$ larger in
conventional beds, all other variables showed that the production was better for the beds
with a significant difference for the fresh mass of the plants, which was $103,430 \mathrm{~g} /$ greater
plant in the economic beds, plant height $3,81 \mathrm{~cm}$, the diameter stem $0.19 \mathrm{~cm}$.

\section{Revista Verde}

ISSN 1981-8203

Pombal, Paraíba, Brasil v. 14, n.2, abr.-jun, p.204-210, 2019

doi: 10.18378/rvads.v14i2.6113 


\section{INTRODUÇÃO}

A alface (Lactuca sativa L.) é uma planta de tamanho herbáceo, pertencente à família Asteraceae. Considerada uma hortaliça folhosa rica em fonte de vitaminas e minerais tendo seu consumo preferencialmente in natura, na forma de salada verde (STAGNARI et al., 2015).

Considerada a folhosa de maior consumo e área plantada no Brasil e no mundo, ocupando desta forma o primeiro lugar na classificação entre os vegetais folhosos mais importantes em termos de valor econômico tanto na produção como na aquisição (WATTHIER et al., 2017).

Dentre os grupos da alface com maior importância econômica, destaca-se a crespa, com $70 \%$ de preferência no mercado brasileiro, seguida da americana (15\%), lisa (10\%) e romana (SUINAGA et al., 2013). Na região nordeste, a alface é tradicionalmente cultivada por agricultores de base familiar que visam agregação da renda, promovendo assim uma grande importância econômica e social (VILLAS BÔAS et al., 2004). Deste modo, a demanda por essa folhosa torna-se imprescindível nas feiras livres e prateleiras de supermercados.

Ao tempo em que é uma cultura de ciclo curto, suas exigências climáticas, bem como as condições de água no solo e nutrientes, tornam-se fatores limitantes para a sua produção. Neste caso, a escolha correta da cultivar, adaptada às condições de clima e solo, associada ao uso da irrigação como forma suplementar, total ou parcial da água, para a planta é fundamental para o sucesso na produção da alface (MAGALHÃES et al., 2015).

O município de Salgueiro - PE, localizado na região Semiárida do Sertão Central de Pernambuco, se apresenta pela problemática em termos de recursos naturais hídricos (LIMA; GATTO, 2014), com precipitação média anual é inferior a 700 $\mathrm{mm}$, distribuída de forma irregular ao longo do ano (ASSIS et al., 2013). Com isto, a prática da irrigação nesta região é de fundamental importância para assegurar a produção agrícola.

Neste sentido, preocupadas com este défice hídrico especialmente para a produção de hortaliças por agricultores familiares no semiárido, as ONGs - Organizações Não Governamentais, como, Patac (Programa de Aplicação de Tecnologia Apropriada às Comunidades) e a Utopia (Unidade Técnica Objetivando Práticas Inovadoras e Adaptadas) desenvolveram um canteiro alternativo, denominado canteiro econômico destinado à produção de hortaliças no semiárido com a máxima economia de água (CRUZ et al., 2014).

O canteiro econômico é uma tecnologia simples confeccionada com tijolos, de largura e extensão variável, contendo entre 0,25 e $0,30 \mathrm{~m}$ de profundidade e impermeabilizado com lona plástica, podendo proporcionar vários benefícios, como melhoria para a produção agrícola, a alimentação e a renda familiar. Mas, apesar das várias vantagens, a irrigação é realizada de forma manual, colocandose água em um tubo que fica enterrado no solo.

Concomitante ao desenvolvimento do canteiro econômico, foi desenvolvido, na Universidade Federal Rural de Pernambuco/Unidade Acadêmica de Serra Talhada (UFRPE/Uast), um sistema de irrigação alternativo para pequenos produtores do semiárido, que mostrou ser até $45 \%$ mais eficiente no uso da água para a produção de mudas de alface em comparação ao sistema de irrigação de microaspersão (LEITE et al., 2018).

Este sistema de irrigação, denominado cuca de umbu, apresenta várias vantagens para os agricultores familiares se comparado com outras tecnologias existentes no mercado, uma vez que "não precisa de energia elétrica para funcionar e, além disso, é automática, ou seja, como a irrigação é subterrânea, o solo é impermeabilizado e se utiliza uma boia. Para controlar a entrada de água no interior do canteiro, o agricultor deve se preocupar apenas em manter cheio o reservatório que o abastece" (LEITE, 2014, p. 21).

A integração do canteiro econômico e o sistema de irrigação cuca de umbu torna-se vantajosa em virtude de suas vantagens e similaridades uma vez que, tais tecnologias podem proporcionar benefícios para pequenos agricultores familiares do semiárido brasileiro, como: eficiência no uso da água, maior produção das hortaliças e facilidade no manejo da irrigação.

Ante o exposto, objetivou-se avaliar a produção de alface no canteiro econômico integrado ao sistema de irrigação cuca de umbu com o canteiro convencional irrigado manualmente com regador em propriedade familiar no município de Salgueiro-PE.

\section{MATERIAL E MÉTODOS}

O experimento foi desenvolvido no período de $1^{\circ}$ de dezembro de 2017 a 17 de janeiro de 2018 em uma propriedade de base familiar, no município de Salgueiro, sertão central de Pernambuco, situada às coordenadas $8^{\circ} 01^{\prime} 56^{\prime \prime}$ de latitude de Sul e 39 $13^{\prime} 51^{\prime \prime}$ de longitude Oeste do meridiano de Greenwich, com aproximadamente 420 metros de altitude.

O clima local se enquadra de acordo com a classificação de Köppen adaptada para o Brasil, no tipo BSwh (semiárido e quente), com temperaturas médias anuais e pluviométricas de $25,3^{\circ} \mathrm{C}$ e $650 \mathrm{~mm}$, respectivamente. O solo da região foi classificado de acordo com Araújo Filho et al. (2000), como Latossolo Vermelho Amarelo de textura argilosa.

O delineamento experimental utilizado foi o de blocos ao acaso, constituído por dois tipos de canteiros: o canteiro econômico integrado ao sistema de irrigação cuca de umbu e o canteiro convencional irrigado manualmente com regador, com quatro repetições, sendo cada repetição constituída de três linhas de sete plantas. A área útil construiu-se de cinco plantas centrais de cada parcela, descartando-se as plantas laterais.

Os canteiros econômicos utilizados nesta pesquisa já existiam na propriedade a cerca de dois anos e foram construídos com $2 \mathrm{~m}$ de comprimento, $1 \mathrm{~m}$ de largura e $18 \mathrm{~cm}$ de profundidade, utilizando blocos de oito furos, cimento e areia. Para evitar problemas de infiltração, foram impermeabilizados com lonas plásticas dupla face (preta e branca) de 150 micras, para distribuição da água no seu interior, foi utilizado um tubo de PVC de $32 \mathrm{~mm}$, perfurado com orifícios de $3 \mathrm{~mm}$ de diâmetro (de um lado para o outro do tubo) espaçados a $20 \mathrm{~cm}$ e, em seguida, coberto com telhas de cerâmica para evitar entupimentos.

Para preenchimento, foi utilizado areia lavada até cobrir a tubulação de distribuição da água conforme a Figura 1 e completado com composto orgânico formado com materiais de serrapilheira e esterco bovino curtido na proporção de 3:1. 
Figura 1. Esquema do canteiro econômico integrado ao sistema de irrigação cuca de umbu

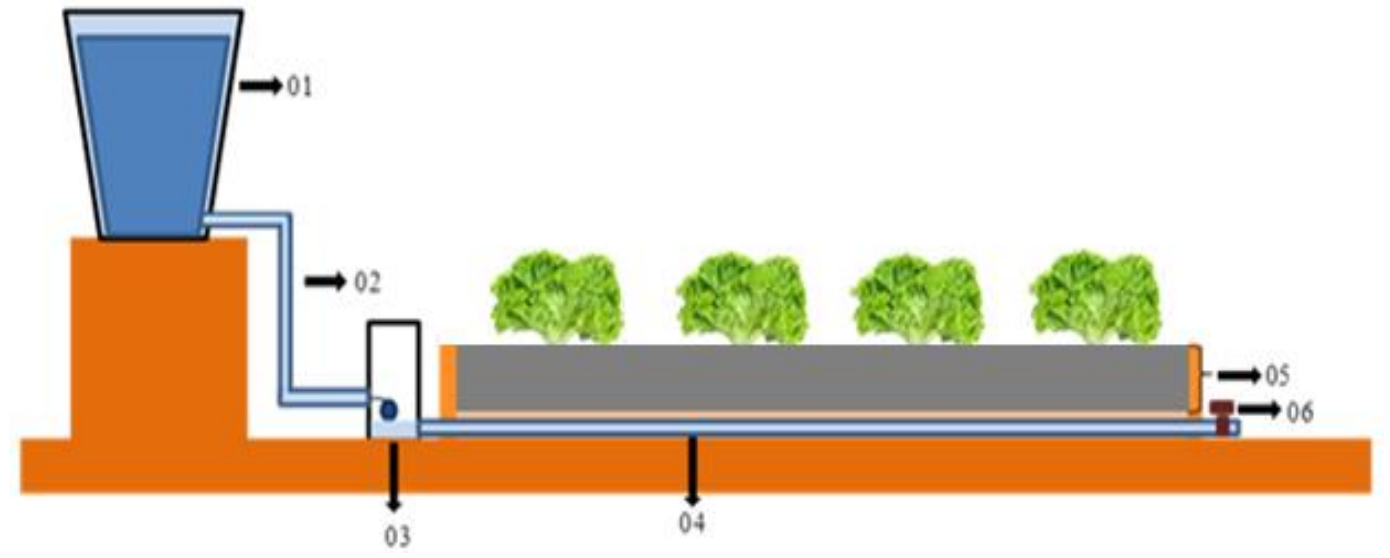

Fonte: Autores, 2018

Descrição do sistema: 1) Reservatório de água que abastece o sistema de irrigação cuca de umbu; 2) Tubulação que conduz água do reservatório para o recipiente com boia; 3) Recipiente com a boia utilizada para controlar o nível da água dentro do canteiro econômico; 4) Tubulação (perfurada) que distribui água dentro do canteiro econômico; 5) Composto orgânico colocado dentro do canteiro econômico sobre a areia lavada; 6) Registro de gaveta utilizado para abrir e fechar o sistema de drenagem.

Os canteiros convencionais tinham dimensão de $2 \times 1 \mathrm{~m}$ (comprimento x largura) e 0,2 $\mathrm{m}$ de altura, nivelados em ambos os lados e construídos um mês antes da realização desta pesquisa para garantir sua consolidação no lugar determinado para a realização deste experimento.
A produção das mudas de alface crespa cv. Veneranda (considerada uma cultivar adaptada aos cultivos de verão com boa resistência ao pendoamento precoce, conforme Ziech et al., 2014) foi realizada semeando-se 5 sementes em recipientes plásticos com volume de $150 \mathrm{ml}$ preenchidos com substrato formado por serrapilheira (SP) cessada, cujas características químicas foram avaliadas no Laboratório de Análise de Solos e Plantas (Lasp), localizado em Petrolina-PE, (Tabela 1), em seguida, acondicionados em bandejas de madeira impermeabilizadas com lona plástica e irrigadas de forma automática, pelo sistema de irrigação cuca de umbu. O transplante das mudas de alface para os canteiros foi realizado 22 dias após a semeadura (DAS), quando as plantas atingiram quatro folhas definitivas no espaçamento de $0,30 \times 0,30 \mathrm{~m}$.

Tabela 1. Características químicas do composto orgânico existente nos canteiros econômicos, da serrapilheira e do esterco bovino utilizados no experimento.

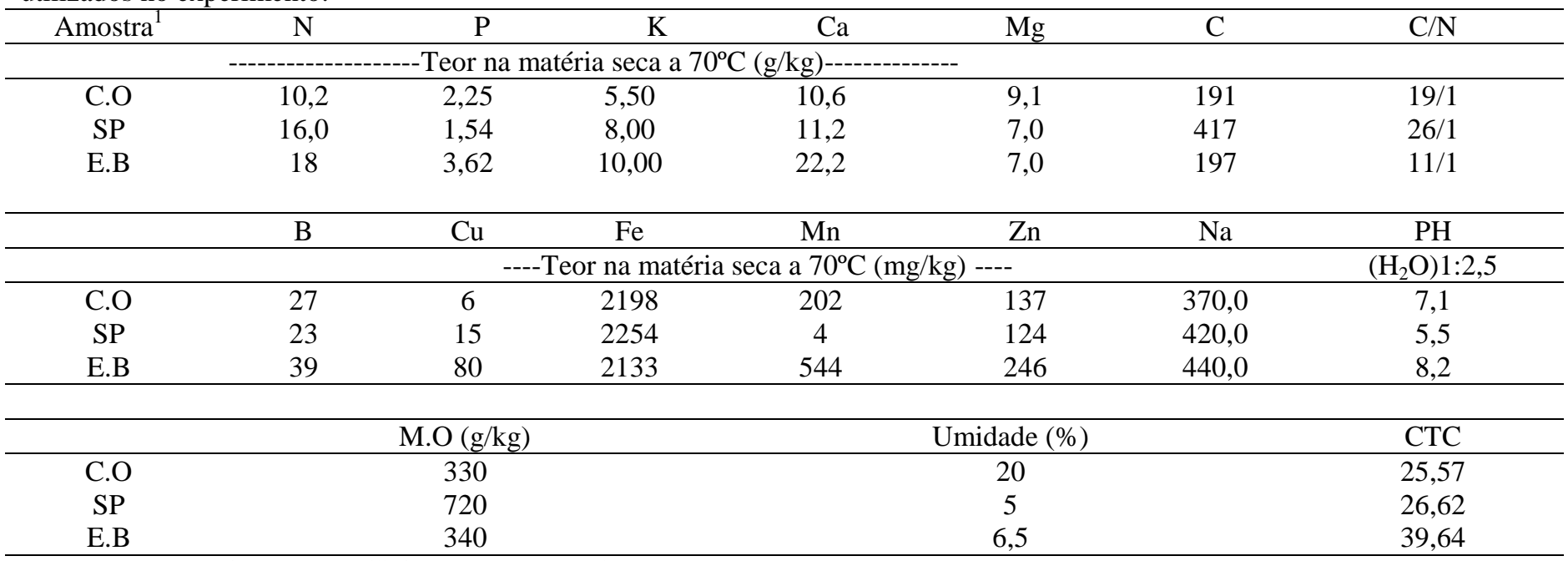

C.O: Composto Orgânico; SP: Serrapilheira; E.B: Esterco Bovino.

A adubação dos canteiros econômicos e convencionais foi realizada 15 dias antes do transplante das mudas, seguindo as orientações de Souza e Resende (2006).

Sendo adicionados a cada canteiro $2 \mathrm{~kg} \mathrm{~m}^{2}$ de esterco bovino e $3,6 \mathrm{~kg}$ de serrapilheira formada por restos de folhas e galhos decompostos de Pau Ferro (Caesalpina Ferrea Mart. ex Tul.).
Apesar de já existir composto orgânico nos canteiros econômicos, a adubação com esterco bovino e serrapilheira serviu para repor os nutrientes perdidos em cultivos anteriores, uma vez que estes canteiros eram utilizados pela família dona da propriedade para produção de hortaliças folhosas, como alface, cebolinha, couve e coentro. 
Para minimizar a evaporação da água, a serrapilheira usada na adubação não foi totalmente incorporada ao solo, e parte dela ficou sobre a superfície do canteiro, servindo como cobertura morta. $\mathrm{O}$ total de material orgânico utilizado forneceu às plantas as seguintes quantidades de macronutrientes: 93,6 $\mathrm{g}$ $\mathrm{m}^{-2}$ de N, $12,78 \mathrm{~g} \mathrm{~m}^{-2}$ de P, 48,8 $\mathrm{g} \mathrm{m}^{-2}$ de K, 84,72 $\mathrm{g} \mathrm{m}^{-2}$ de Ca, e $39,2 \mathrm{~g} \mathrm{~m}^{-2}$ de $\mathrm{Mg}$.

O manejo da irrigação nos canteiros convencionais foi realizado por meio da evapotranspiração de referência (ETo) diária, estimado pelo método padrão de Penman-Monteith recomendado pela FAO, conforme afirma Allen et al. (1998), a partir das informações meteorológicas fornecidas pelo Instituto Nacional de Meteorologia (INMET), através da estação meteorológica de superfície automática da cidade de SalgueiroPE. Os dados de precipitação foram registrados através de um pluviômetro instalado no local do experimento e logo após o transplante das mudas de alface para os canteiros.

Conforme pode ser observado na Figura 2, são apresentadas a distribuição temporal das variáveis climáticas de umidade relativa e temperatura máxima e mínima, que provocaram respostas ao consumo hídrico da cultura para os canteiros econômicos e convencionais durante o período de estudo.

Figura 2. Temperatura máxima, mínima $\left({ }^{\circ} \mathrm{C}\right)$ e umidade relativa (\%) máxima e mínima diárias no período experimental.

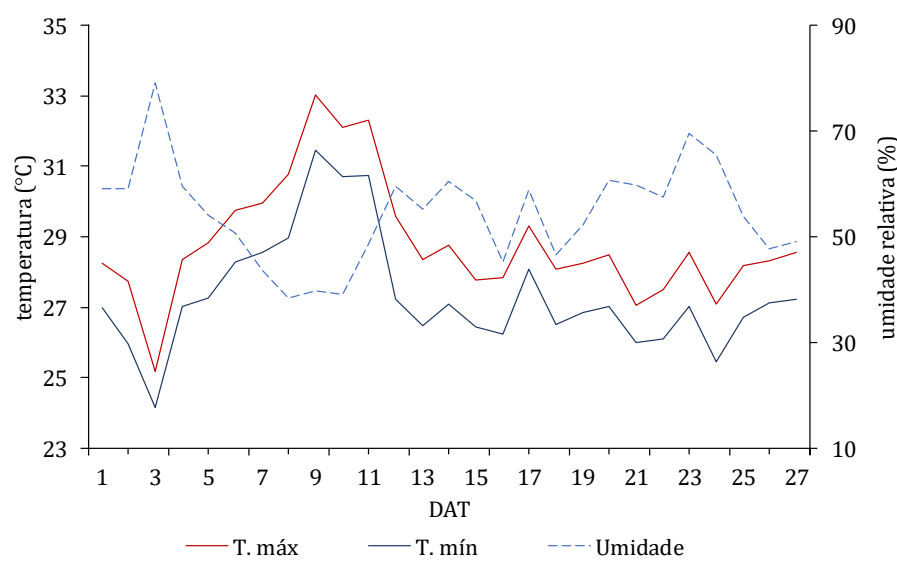

A maior temperatura registrada no período experimental foi de $37,9^{\circ} \mathrm{C}$, e a mínima de $20,1^{\circ} \mathrm{C}$. Para a umidade relativa do ar, a máxima e mínima encontradas foram de 96 e 19\%, respectivamente.

Para os canteiros econômicos, a irrigação foi realizada, mantendo-se intermitentemente uma lâmina de água de $6 \mathrm{~cm}$ de profundidade no interior do canteiro, ficando $12 \mathrm{~cm}$ de material orgânico, servindo como condutor hidráulico. A quantidade de água utilizada foi determinada através da reposição diária de um recipiente, com capacidade para $30 \mathrm{~L}$. Utilizou-se, como fonte hídrica, a água da chuva armazenada em uma cisterna calçadão, com capacidade para $52 \mathrm{~m}^{3}$.

Ao final do ciclo vegetativo da cultura da alface, 26 dias após o transplante (DAT), as plantas foram coletadas e levadas até o laboratório de tecnologia em alimentos do Instituto Federal de Educação, Ciência e Tecnologia do Sertão de Pernambuco, campus Salgueiro/PE.
Foram avaliadas as seguintes variáveis: número médio de folhas por planta, determinado manualmente, contando-se o número de folhas com tamanho mínimo de $2 \mathrm{~cm}$; altura média de plantas $(\mathrm{cm})$, determinada medindo-se da altura do colo até o final da folha mais alta; diâmetro da planta $(\mathrm{cm})$, determinado pelo tamanho da área ocupada pela planta; diâmetro do caule $(\mathrm{cm})$, determinado por meio de um corte transversal na parte mais espessa; massa fresca de parte aérea e de raiz;; massa seca da parte aérea e de raiz, provenientes da matéria fresca, após o material ser levado para secar em estufa, com circulação forçada de ar, a $65^{\circ} \mathrm{C}$, até obter peso constante; comprimento da raiz, determinado, medindo-se a área entre o final do caule e o final da última raiz.

A eficiência no uso da água (EUA) $\left(\mathrm{kg} \mathrm{ha}^{-1} \mathrm{~mm}^{-1}\right)$ foi obtida pela razão da massa fresca total da cultura da alface pela lâmina total aplicada para cada tratamento, conforme a equação (1).

$$
\text { EUA }\left(\mathrm{kg} \mathrm{ha}^{-1} \mathrm{~mm}^{-1}\right)=\frac{P}{\mathrm{I}+\mathrm{Pe}}
$$

Em que: $\mathrm{P}=$ produtividade da cultura $\left(\mathrm{kg} \mathrm{ha}^{-1}\right) ; \mathrm{I}=$ lâmina aplicada pela irrigação $(\mathrm{mm})$; e Pe = precipitação efetiva $(\mathrm{mm})$.

Os resultados foram analisados, através do teste $\mathrm{t}$ de Student, em nível de significância de 5\% de probabilidade, utilizando-se o programa estatístico Sisvar ${ }^{\circledR}$ (FERREIRA, 2011).

\section{RESULTADOS E DISCUSSÃO}

Os resultados das lâminas aplicadas no manejo da água para o canteiro econômico e convencional estão destacados da Figura 3. Houve uma precipitação de $50 \mathrm{~mm}$, que promoveu uma melhor aclimatação das mudas em campo (Figura 3). Sendo que durante todo o experimento, ocorreram três precipitações $(01,17$ e $23 \mathrm{DAT})$, totalizando $67 \mathrm{~mm}$ de água pluvial. Apesar disso, a lâmina efetiva, que se refere ao volume de água realmente utilizado pela planta durante seus processos fisiológicos, foi estabelecida pela evapotranspiração diária da cultura (BERNARDO et al., 2008).

A diferença dessa lâmina e a precipitação pluviométrica é considerada o volume de água que foi perdido por percolação e/ou escoamento superficial. Desta forma, dos $67 \mathrm{~mm}$ precipitados, apenas $14 \mathrm{~mm}$ estiveram efetivamente disponíveis para as plantas.

Os valores acumulados para o canteiro econômico foram superiores ao do canteiro convencional, com acumulados de $167,558 \mathrm{~mm}$ e 123,328 mm, respectivamente (Figura 3).

A partir do décimo nono dia após o transplantio, a necessidade hídrica da alface no canteiro econômico dobrou em relação ao do canteiro convencional. Percebe-se que este comportamento teve relação direta com o diâmetro da planta (Tabela 2), que foi maior em relação ao canteiro convencional, promovendo, assim, uma maior evapotranspiração. 
Figura 3. Lâmina aplicada para o canteiro econômico e convencional e precipitação efetiva ao longo do ciclo da cultura da alface $c v$. Veneranda.

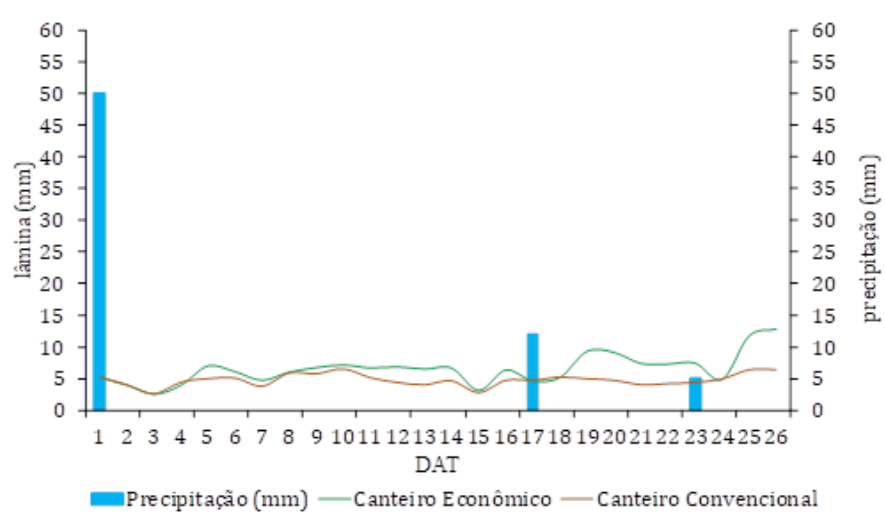

Em trabalho realizado por Gonçalves et al. (2014), avaliando a irrigação no cultivo orgânico de alface no município de Seropédica-RJ, utilizando o sistema Irrigás, tanque Classe A e um sistema automático de baixo custo, obtiveram produção com lâminas totais de $129 \mathrm{~mm}, 130 \mathrm{~mm}$ e $121 \mathrm{~mm}$, respectivamente.

É importante enfatizar que a cultura da alface é cultivada por pequenos produtores, os quais necessitam de métodos operacionais de baixo custo e fácil operacionalidade. Deste modo, o canteiro econômico integrado ao sistema de irrigação cuca de umbu necessita apenas da reposição da lâmina nos reservatórios quando apresentarem déficit de água, enquanto o canteiro convencional necessita de conhecimentos prévios de dados climáticos e fenológicos para a reposição do consumo hídrico requerido pela cultura.

Os resultados de número de folhas (NF); altura da planta (AP); diâmetro da planta (DP); diâmetro do caule (DC) e comprimento da raiz (CR) estão destacados na Tabela 2 . Conforme os resultados da análise de variância, nota-se que não houve efeito significativo para as variáveis de altura de plantas (AP) e diâmetro do caule (DC). Apesar de não haver diferença significativa entre os dois canteiros para o número de folhas (NF) e diâmetro da planta (DP), observa-se que os resultados foram superiores para canteiro econômico, quando comparado ao canteiro convencional, com média respectivamente de 29 folhas planta ${ }^{-1}$ e diâmetro de 43,10 cm (Tabela 2).

Tabela 2. Número de Folhas (NF); Altura de Planta (AP); Diâmetro da Planta (DP); Diâmetro do Caule (DC); e Comprimento da Raiz (CR) da cultura da alface, cv. Veneranda, em função dos tipos de canteiro

\begin{tabular}{lccccc}
\hline \multirow{2}{*}{ Canteiros } & NF & AP & DP & DC & CR \\
\cline { 2 - 6 } & Folhas/planta & \multicolumn{4}{c}{$(\mathrm{cm})$} \\
\hline Econômico & $29,0 \mathrm{a}$ & $22,03 \mathrm{a}$ & $43,10 \mathrm{a}$ & $2,73 \mathrm{a}$ & $17,53 \mathrm{~b}$ \\
C.V $(\%)$ & 6,19 & 9,17 & 7,48 & 3,51 & 0,11 \\
\hline Convencional & $27,0 \mathrm{a}$ & $18,22 \mathrm{~b}$ & $39,74 \mathrm{a}$ & $2,53 \mathrm{~b}$ & $19,72 \mathrm{a}$ \\
C.V $(\%)$ & 3,96 & 3,90 & 0,90 & 3,79 & 0,03 \\
\hline
\end{tabular}

*ns = não significativo ao teste $(\mathrm{t})$ a $5 \%$ de probabilidade.

Revista Verde, v.14, n.2, p.204-210, 2019
Esses valores foram superiores às encontradas por Sousa (2017), o qual obteve 21,2 folhas planta ${ }^{-1}$ com diâmetro de 23,2 cm, após 39 dias após o transplantio (DAT) para a variedade Veneranda quando irrigada pela aspersão do tipo convencional em uma propriedade rural no município de Jataí-GO. Estes resultados mostram que a cultivar crespa tende a se desenvolver rapidamente e a produzir maior número de folhas em regiões de clima mais quente, comprovando a teoria de Queiroz et al. (2014), onde nota-se que a temperatura do presente local de estudo foi de $29,15^{\circ} \mathrm{C}$, enquanto que em Jataí/GO, a temperatura média foi igual a $27,25^{\circ} \mathrm{C}$, sendo assim, considerado um dos fatores determinantes para o maior número de folhas em um menor período de tempo.

Para as variáveis altura da planta (AP); diâmetro do caule (DC) e comprimentos da raíz, houve diferença significativa entre os canteiros. Para a altura das plantas nos canteiros econômicos e convencionais, observou-se que a média nos canteiros econômicos $(22,03 \mathrm{~cm})$, foi $3,81 \mathrm{~cm}$ superior às plantas dos canteiros convencionais $(18,22 \mathrm{~cm})$.

Resultados semelhantes a estes foram encontrados por Magalhães et al. (2015) na região do Chapadão do Sul, MS, que após 66 dias do transplantio da cultivar Rapids, a altura média das plantas foi de 22,83 e $26 \mathrm{~cm}$ para a irrigação com lâmina de irrigação com $100 \%$ e $125 \%$ da ETc, respectivamente.

Ao analisar o diâmetro do caule, foi observado uma diferença de $0,20 \mathrm{~cm}$ quando comparado a média dos valores obtidos para o canteiro econômico $(2,73 \mathrm{~cm})$ quando comparada com a média dos canteiros convencionais $(2,53 \mathrm{~cm})$. Estes resultados foram superiores aos encontrados por Cavalheiro et al. (2015), que, ao avaliar o diâmetro do caule da cultivar Vanda em diferentes ambientes e níveis de adubação mineral e orgânica, constataram que o maior diâmetro foi de $1,27 \mathrm{~cm}$, encontrado nas plantas cultivadas em ambiente protegido adubadas com adubação mineral, NPK.

Para o comprimento das raízes, o resultado mostrou que as raízes das plantas dos canteiros convencionais, foi superior 2,19 $\mathrm{cm}$ quando comparado as do canteiro econômico, com médias de $19,72 \mathrm{~cm}$ e $17,53 \mathrm{~cm}$, respectivamente.

O menor comprimento da raiz no canteiro econômico pode estar relacionado à maior zona de umidade na superfície deste canteiro em virtude da elevação do lençol freático. Em trabalho realizado por Linhares et al. (2013) avaliando o crescimento da cultivar Elba, grupo crespa, em canteiros do tipo leirões, obtiveram resultados de crescimento das raízes de $15,84 \mathrm{~cm}$, sendo inferior ao resultado do canteiro convencional para esse estudo.

Neste sentido, o menor crescimento das raízes nos canteiros econômicos, em comparação com o tamanho das raízes do canteiro convencional, não afetou o crescimento da parte aérea das plantas, o qual foi superior no canteiro econômico.

Os resultados de massa fresca e seca da folha e raiz encontram-se na Tabela 3. Nota-se que houve diferença significativa na análise da massa fresca das plantas nos canteiros econômicos $(426,48 \mathrm{~g})$ quando comparado com as plantas dos canteiros convencionais $(323,05 \mathrm{~g})$ de $103,430 \mathrm{~g}$ (Tabela 3).

Lima et al. (2009) avaliando a produção de alface com diferentes lâminas no município de Seropédica-RJ, obtiveram 
uma produção de 457,14 $\mathrm{g}$ planta $^{-1}$, correspondente a $7,31 \mathrm{~kg} \mathrm{~m}^{-}$ ${ }^{2}$, com uma lâmina total de $131,8 \mathrm{~mm}$ (80 a $100 \%$ da ETc) em canteiros com cobertura morta, enquanto que no presente trabalho a maior produção foi obtida nos canteiros econômicos com 426,48 $\mathrm{g}$ planta $^{-1}$, equivalente a $4,53 \mathrm{~kg} \mathrm{~m}^{-2}$, utilizando uma lâmina total de $167,558 \mathrm{~mm}$ e para os canteiros convencionais com lâmina total de $123,328 \mathrm{~mm}$, utilizando $100 \%$ da ETc e coeficiente de cultivo $(\mathrm{KC}=1)$ da fase de transplantio até a colheita das hortaliças com uma produção foi de 323,05 g planta ${ }^{-1}$, equivalente a $3,434 \mathrm{~kg} \mathrm{~m}^{-2}$.

Ao comparar os dados de produção de massa fresca encontrados neste trabalho com os dados de produção de Lima et al. (2009) e Resende et al. (2017), nota-se que as variáveis climáticas, especialmente a temperatura, foi um fator determinante para baixa produção no presente trabalho.

Corroborando com este entendimento, Silva et al. (2000) afirmam que a temperatura pode ter influência direta no peso, qualidade, arquitetura e principalmente na produção da cultura da alface.

Embora houvesse uma maior produção da alface nos canteiros econômicos em comparação com os canteiros convencionais, a utilização de uma tela de sombreamento para reduzir a incidência de luz durante o período mais quente do ano, em regiões de clima semiárido poderá proporcionar uma maior produção.

Para a massa seca das folhas, massa fresca e seca das raízes, nota-se que não houve diferença significativa. Os valores médios de massa seca das folhas nos canteiros econômicos foram de $28,95 \mathrm{~g}$, sendo superior ao canteiro convencional em $0,91 \mathrm{~g}$. Atribui-se o fato de ter havido diferença significativa na MFF devido a água está disponível com frequência para a planta. Para a média da massa fresca das raízes nos canteiros econômicos em relação ao convencional, os valores obtidos foram de 17,54 g e 15,15 g, respectivamente.

Estes resultados foram superiores aos encontrados por Santos et al. (2015), que constataram que o peso médio da massa fresca da raiz da alface americana foi de $11,4 \mathrm{~g} \mathrm{planta}^{-1,}$ utilizando $150 \%$ da ETc da fase de transplante até a colheita.

Tabela 3. Massa Fresca da Folha (MFF); Massa Seca da Folha (MSF); Massa Fresca da Raiz (MFR); e Massa Seca da Raiz (MSR) da cultura da alface, cv. Veneranda, em função dos tipos de canteiro.

\begin{tabular}{lcccc}
\hline \multirow{2}{*}{ Tipo de canteiro } & MFF & MSF & MFR & MSR \\
\cline { 2 - 5 } & \multicolumn{4}{c}{$(\mathrm{g})$} \\
\hline Econômico & 426,48 & $28,95^{\mathrm{ns}}$ & $17,54^{\mathrm{ns}}$ & $5,41^{\mathrm{ns}}$ \\
C.V $(\%)$ & 15,01 & 11,01 & 21,92 & 11,50 \\
\hline Convencional & 323,05 & 28,04 & 15,15 & 4,96 \\
C.V $(\%)$ & 5,75 & 1,44 & 3,66 & 3,16 \\
\hline
\end{tabular}

*ns = não significativo ao teste $(\mathrm{t})$ a $5 \%$ de probabilidade.

As médias da massa seca da raiz nos canteiros econômicos e convencionais, foram de 5,41 g e 4,96 g, respectivamente. Esses valores foram superiores aos resultados encontrados por Santos et al. (2015), que constataram que o peso médio da massa seca da raiz da alface americana com $150 \%$ da ETc foi de 2,4 gramas $^{-1}$.
Embora a produção tenha sido maior nos canteiros econômicos, a eficiência no uso da água foi de $270,557 \mathrm{~kg} \mathrm{ha}^{-1}$ $\mathrm{mm}^{-1}$, enquanto que nos canteiros convencionais foi de 278,476 $\mathrm{kg} \mathrm{ha}^{-1} \mathrm{~mm}^{-1}$, ou seja, nestes últimos, a eficiência no uso da água foi $2,92 \%$ maior, quando comparado com o canteiro anterior.

Para o presente trabalho, pode-se afirmar que embora não tenha havido perda de água por infiltração nos canteiros econômicos, o total de água perdido pela evapotranspiração foi superior à infiltração e a evapotranspiração dos canteiros convencionais, neste sentido torna-se importante a realização de novas pesquisas com o objetivo de determinar a melhor espessura do condutor hidráulico ou a melhor cobertura para redução da perda de água para a atmosfera nos canteiros econômicos.

\section{CONCLUSÃO}

Os canteiros econômicos proporcionam maior produção de alface com plantas que apresentam melhores características agronômicas comparadas as cultivadas em canteiros convencionais.

\section{REFERÊNCIAS}

ASSIS, J. M. O.; SILVA, R. F.; SOUSA, W. S.; IRMÃO, R. A.; CORREIA, A. M. Tendências Climáticas Observadas no Período Chuvoso no Sertão de Pernambuco. Revista Brasileira de Geografia Física, v. 06 n. 02, p. 211-222, 2013.

ALLEN, R. G.; PEREIRA, L. S.; RAES, D.; SMITH, M. Crop evapotranspiration: Guidelines for computing crop water requirements. Rome: FAO, 1998. 300 p.

ARAÚJO FILHO, J. C.; BURGOS, N.; LOPES, O. F.; SILVA, F. H. B. B.; MEDEIROS, L. A. R.; MELO FILHO, H. F. R.; PARAHYBA, R. B. V.; CAVALCANTI, A. C.; OLIVEIRA NETO, M. B.; SILVA, F. B. R. LEITE, A. P.; SANTOS, J. C. P.; SOUSA NETO, N. C.; SILVA, A. B.; LUZ, L. R. Q. P.; LIMA, P. C.; REIS, R. M. G.; BARROS, A. H. C. Levantamento de reconhecimento de baixa e média intensidade dos solos do Estado de Pernambuco. Rio de Janeiro: Embrapa Solos, 2000. $378 \mathrm{p}$.

BERNARDO, S.; SOARES, A. A.; MANTOVANI, E. C. Manual de irrigação. 8.ed. Viçosa: Editora UFV, 2008. 625p.

CAVALHEIRO, D. B.; KLOSOWSKI, É. S.; HENKEMEIER, N. P.; GONÇALVES JUNIOR, A. C.; VASCONCELOS, E. S.; CHIBIAQUI, E. Produção de alface (Lactuca sativa L.) cv. Vanda, cultivada sob diferentes ambientes e níveis de adubação mineral e orgânica. Cultivando o Saber, v. 8. n.1, p. 109 - 124, 2015.

CRUZ, M. P.; CRUZ, K. R. P.; PEREIRA, T. C.; MARINHO, F. J. L. Utilização de Canteiro Econômico como uma tecnologia alternativa para o semiárido. In: CONGRESSO DE EDUCAÇÃO AGRÍCOLA SUPERIOR, 9, 2014, Areia, PB. Anais... Areia, PB: ABEAS, 2014. 
FERREIRA, D. F. Sisvar: a computer statistical analysis system. Revista Ciência e Agroecologia, v.35, n.6, p.10391043, 2011. http://dx.doi.org/10.1590/S1413$\underline{70542011000600001}$

GONÇALVES, F. V.; MEDICI, L. O.; ALMEIDA, W. S.; CARVALHO, D. F.; SANTOS, H. T.; GOMES, D. P. Irrigação no cultivo orgânico de alface, utilizando Irrigás, tanque Classe A e um sistema automático de baixo custo. Revista Ciência Rural, v.44, n.11, p.1950-1955, 2014. http://dx.doi.org/10.1590/0103-8478cr20131448

LIMA, J. P. R.; GATTO, M. F. A economia do Semiárido de Pernambuco: ainda "sem produção"?. Revista Economia e Desenvolvimento, v. 13, n. 1, p.130-167, 2014.

LIMA, M. E.; CARVALHO, D. F.; SOUZA, A. P.; GUERRA, J. G. M.; RIBEIRO, R. L. D. Desempenho da alface em cultivo orgânico com e sem cobertura morta e diferentes lâminas d'água. Ciência Agrotecnologia, v. 33, n. 6, p. 1503-1510, 2009. https://doi.org/10.1590/S1413-70542009000600007.

LEITE, D. de C.; BARROS JÚNIOR, G.; OLIVEIRA, R. H. Desenvolvimento de um sistema alternativo de irrigação para pequenos produtores do semiárido. Scientia Plena, v.14,n.7,p.112,2018. https://doi.org/10.14808/sci.plena.2018.070202.

LEITE, D. de C. Experimentação da tecnologia de irrigação cuca de umbu por agricultores familiares do semiárido de Pernambuco. 2014. 85 f. Dissertação (Mestrado em Extensão Rural e Desenvolvimento Local) - Universidade Federal Rural de Pernambuco, Recife. 2014.

LINHARES, P. C. A.; SILVA, J. N. da; FIGUEREDO, J. P. de; SOUZA, J. A. de; SANTOS, J. G. R. dos; SOUSA, T. P. de; MARACAJÁ, P. B. Crescimento da alface (Lactuca sativa), sob adubação orgânica em condições edafoclimáticas de Catolé do Rocha-PB. Revista Brasileira de Gestão Ambiental, v.7, n.4, p. 17-22, 2013.

MAGALHÃES, F. F.; CUNHA, F. F. GODOY, A. R.; SOUZA, E. J.; SILVA, T. R. Produção de cultivares de alface tipo crespa sob diferentes lâminas de irrigação. Water Resources and Irrigation Management, v.4, n.1-3, p.41-50, 2015. https://:doi:10.19149/2316-6886/wrim.v4n1-3p41-50.

QUEIROZ, J. P. S.; COSTA, A. J. M. da; NEVES, L. G.; JUNIOR, S. S.; BARELLI, M. A. A. Estabilidade fenotípica de alfaces em diferentes épocas e ambientes de cultivo. Revista Ciência Agronômica, v. 45, n. 2, p. 276-283, 2014.

RESENDE, G. M.; COSTA, N. D.; YURI, J. E.; MOTA, J. H. Adaptação de genótipos de alface crespa em condições semiáridas. Revista Brasileira de Agricultura Irrigada, v.11,n.1,p.1145-1154,2017.

https://doi.org/10.7127/rbai.v11n100553.
STAGNARI, F., GALIENE, A., AND PISANTE, M. Shading and nitrogen management affect quality, safety and yield of greenhouse-grown leaf lettuce. Scientia Horticulturae, v.192, n.3, p.70-79, 2015. https://dx.doi.org/10.1016/j.scienta.2015.05.003.

SANTOS, M. A. L.; SANTOS, D. P.; MENEZES, S. M.; LIMA, D. F.; VIEIRA, J. P. S. Produção da cultura da alface (Lactuta sativa L.), em função das lâminas de irrigação e tipos de adubos. Ciência Agrícola, v. 13, n. 1, p. 33-39, 2015. http://doi.org/10.28998/rca.v13i1.1652.

SILVA, V.F.; BEZERRA NETO, F.; NEGREIROS, M.Z.; PEDROSA, J.F. Comportamento de cultivares de alface em diferentes espaçamentos sob temperatura e luminosidade elevadas. Horticultura Brasileira, v.18, n. 3, p.183-187, 2000.

SOUZA, J. L.; RESENDE, P. Manual de Horticultura Orgânica. 2.ed. Viçosa: Aprenda Fácil, 2006. 843 p.

SOUSA, V. S. Desempenho de cultivares de alface do grupo solta crespa para cultivo no verão em Jataí-GO. 2017. $16 \mathrm{f}$. Dissertação (Mestrado em Agronomia) - Universidade Federal de Goiás, Jataí. 2017.

SUINAGA, F. A.; BOITEUX, L. S.; CABRAL, C. S.; RODRIGUES, C. da S. Métodos de avaliação do florescimento precoce e identificação de fontes de tolerância ao calor em cultivares de alface do grupo varietal crespa. Brasília, DF: Embrapa Hortaliças, 2013. 4 p. (Embrapa Hortaliças. Comunicado Técnico, 89).

VILLAS BÔAS, R. L.; PASSOS, J. C.; FERNANDES, M.; BÜLL, L. T.; CEZAR, V. R. S.; GOTO, R. Efeito de doses e tipos de compostos orgânicos na produção de alface em dois solos sob ambiente protegido. Horticultura Brasileira, v.22, n.1, p.28-34, 2004.

WATTHIER M.; SILVA, M.A.S.; SCHWENGBER, J. E.; FERMINO, M. H. Produção de mudas de alface em substratos com base de composto de tungue em sistema orgânico de produção, sem período de verão. Horticultura Brasileira, v.35, n.2, p.290-294, 2017.

ZIECH, A. R. D.; CONCEIÇÃO, P. C.; LUCHESE, A. V.; PAULUS, D.; ZIECH, M. F. Cultivo de alface em diferentes manejos de cobertura do solo e fontes de adubação. Revista Brasileira de Engenharia Agrícola e Ambiental, v. 18, n. 9, p. 948-954, 2014. http://dx.doi.org/10.1590/18071929/agriambi.v18n09p948-954. 